\title{
HIV/AIDS IN THE COUNTRIES OF THE FORMER SOVIET UNION: SOCIETAL AND ATTITUDINAL CHALLENGES
}

\author{
Bernd Rechel \\ European Observatory on Health Systems and Policies and London School of Hygiene \& Tropical Medicine, Keppel Street, UK
}

\section{SUMMARY}

For several years, some of the countries of the former Soviet Union have experienced the fastest growing HIV epidemic in the world, with the vast majority of reported infections contracted through injecting drug use. However, most governments of the region have been slow to recognize the severity of the problem. The scope and coverage of governmental HIV/AIDS programmes have remained very limited. Harm reduction programmes are mainly financed by external donors, while substitution treatment remains illegal in Russia and unavailable in some other countries of the region.

Being based on a review of published and grey literature, this paper explores attitudinal and societal barriers to scaling up HIV programmes in the countries of the former Soviet Union. A major challenge in many countries is negative public attitudes towards people living with HIV, as well as towards those most at risk of contracting the disease: injecting drug users, sex workers, and men who have sex with men. This extends to the actions of state authorities which often pursue a punitive approach to drug users, with high rates of incarceration for minor drug offences. While many of the findings reported here relate to the Russian Federation, there is reason to believe that similar challenges existin many other countries of the former Soviet Union. More needs to be done to document challenges to HIV prevention and treatment programmes across the region, so that policy interventions can be more effective.

Key words: Central and Eastern Europe, former Soviet Union, HIV/AIDS, prejudice, discrimination

Address for correspondence: B. Rechel, London School of Hygiene and Tropical Medicine, Keppel Street, London WC1E 7HT, United Kingdom. E-mail: Bernd.Rechel@Ishtm.ac.uk

\section{INTRODUCTION}

For several years, some of the countries of the former Soviet Union had the fastest growing HIV epidemics worldwide. In 2008, 1.5 million (1.4 million-1.7 million) people were estimated by UNAIDS to be living with HIV in Eastern Europe and Central Asia, about $90 \%$ of whom were in the Russian Federation and Ukraine (1). Of the new HIV cases reported in 2007 for which information was available on the mode of transmission, 57\% were attributed to injecting drug use (1) (Fig. 1).

Most governments in the region have been slow to recognize the scale and severity of the problem (2) and only in recent years has political commitment been growing (3). In Russia, for example, a high-level Governmental Commission on AIDS was established in October 2006 and federal funding for the national AIDS response increased 40 times between 2005 and 2007. Yet despite this increased political commitment, the scale and scope of HIV programmes remains inadequate, in particular with regard to harm reduction measures, substitution treatment and antiretroviral treatment $(4,5)$.

When trying to understand why many countries of the region have been so slow to wake up to the enormous threat the HIV epidemics bring to their societies, it becomes apparent that this had to do with the population groups considered to be at highest risk of contracting the disease: injecting drug users and sex workers. Similar to initial reactions to HIV in Western societies, such as the United States (6), the predominant belief among policy-makers and the public in the former Soviet Union was that HIV was not an issue that concerned the general population and required an immediate and comprehensive response. These predominant attitudes seem to be an important barrier to successful HIV pro-

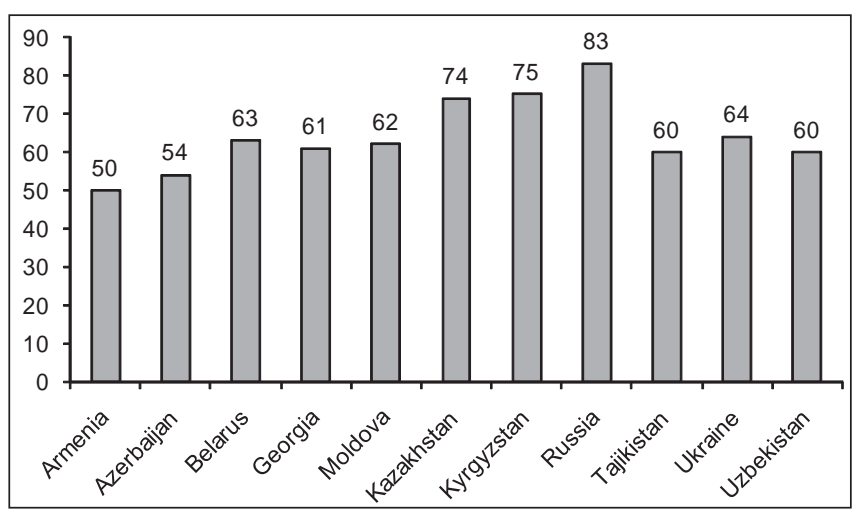

Fig. 1. Injecting drug users as a percentage of total HIV cases in 2007. (Source 4) 
grammes in this part of Europe (7). Many of these attitudinal challenges have been described in the literature, but these descriptions have remained scattered, with no comprehensive discussion of the relevant issues. This paper aims to bring together the current knowledge about how negative attitudes towards people living with HIV, as well as towards those most at risk of contracting the disease, act as a barrier to HIV programmes in countries of the former Soviet Union.

\section{MATERIAL AND METHODS}

This article is based on a review of published and grey literature. The identification of documents started with a search of the Pubmed/Medline database in January 2010, using the MeSH terms "HIV" AND "Eastern Europe", as well as "HIV" AND "Central Asia", and being limited to English language articles published between 2003 and 2009. Titles and abstracts (where available) were screened for relevance and papers were included in the review when found relevant to the societal and attitudinal dimension of HIV/AIDS in the countries of the former Soviet Union. Papers were excluded when they mainly dealt with bio-medical aspects, the cost-effectiveness of interventions, or epidemiological aspects of the HIV epidemic. The search was continued iteratively by screening reference lists of selected articles. The search of documents was complemented by a search of grey literature, using Google/Google Scholar and, in various combinations, the search terms "HIV", "Central and Eastern Europe”, “prejudice”, “discrimination”, and “stigma”. In addition, documents were retrieved from the internet sites of UNAIDS and the Open Society Institute Harm Reduction Programme. As data from both quantitative and qualitative sources were used, attention was paid to the challenge of integrating these data sets while recognizing the limitations of the research approach taken (8). Another limitation of the findings presented here is that most of the published literature is concerned with the Russian Federation, with less attention given to other countries of the former Soviet Union. Despite these limitations, the chosen research approach allowed to review different types of evidence with the aim of generating insights and informing policy (9).

\section{RESULTS}

\section{A Punitive Approach to Injecting Drug Use and HIV}

One of the major barriers to improving access to HIV prevention and treatment activities in the former Soviet Union is the predominance of a punitive approach to injecting drug use and people living with HIV (6). This approach is also reflected in the availability of antiretroviral treatment for HIV patients (10). While in many countries worldwide injecting drug users are disproportionately less likely to receive antiretroviral treatment for HIV/AIDS than other patients, some of the highest discrepancies can be found in Russia (11). According to the UNGASS country reports, coverage of people with advanced HIV infection receiving antiretroviral therapy in the Russian Federation was only 2-7\% in 2004, although it increased to a reported 10-25\% in 2007 (5).

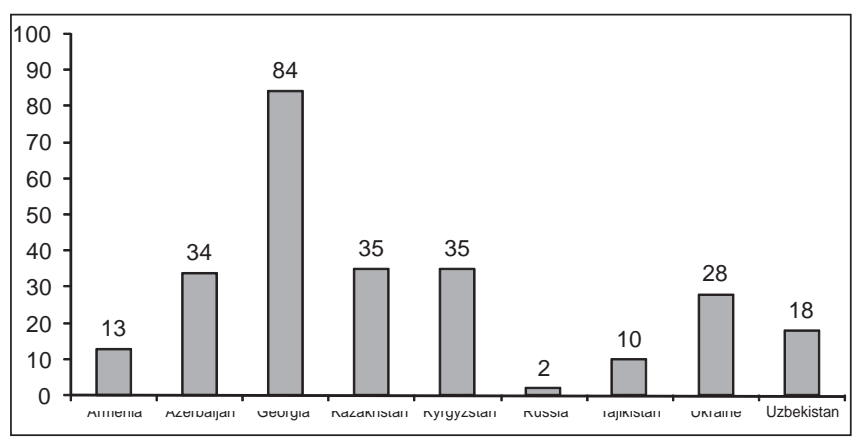

Fig. 2. Percentage of injecting drug users reached by HIV prevention services, 2006. (Source 4)

Coverage with harm reduction programmes also remains low in many countries of the region, with the lowest coverage reported in Russia (Fig. 2). According to a 2007 Global Fund estimate, overall coverage of harm reduction measures in Eastern Europe and Central Asia was at best only $9 \%$, with coverage falling to $2 \%$ in the Russian Federation (4). Most harm reduction programmes are implemented by externally funded NGOs or government-organized NGOs (GONGOs), while national funding has remained scant (4). Harm reduction interventions in Russia began in the mid-1990s and had increased to 80 pilot projects a decade later. However, harm reduction has so far not been formally integrated into the national HIV policy (12). Furthermore, while federal funds for HIV programmes in Russia increased substantially between 2004 and 2006, resources for harm reduction interventions decreased by $27 \%$ in the same period (12). In the case of both Belarus and Kazakhstan, needle and syringe exchange programmes have been included in the national AIDS programmes, but by 2007 substantial budgetary funding had not been forthcoming (13). Some of the difficulties harm reduction programmes in the region have been experiencing related to their unclear legal status which gave law enforcement agencies an opportunity to disrupt harm reduction projects (12). Article 230 of the 1996 Russian Criminal Code made "inclining to consumption" of illegal narcotics an offense and an explanatory note was only added in 2003 that formally recognized the distribution of drug injecting equipment for the purpose of HIV prevention $(14,15)$.

Substitution treatment with buprenorphine or methadone remains largely unavailable in the former Soviet Union $(5,13)$. Kyrgyzstan in 2001 was the first country in the Commonwealth of Independent States (CIS) that started with substitution treatment. However, in the Russian Federation and Turkmenistan substitution treatment remains prohibited by law $(4,12,13,16)$ and, as of 2007, it remained unavailable in Armenia, Kazakhstan and Tajikistan (4).

Instead, drug treatment and rehabilitation services are outdated, draconian and seemingly ineffective $(11,17)$. They fall into the remit of "narcology", a Soviet subspecialty of psychiatry, that puts an emphasis on short-term detoxification in narcological dispensaries with practically no follow-up $(11,16,18,19)$. In some countries of the region, such as Uzbekistan, such treatment is compulsory for injecting drug users apprehended by the police (4). Drug treatment services have historically close ties with law enforcement agencies and breaches in patient confidentiality are common $(14,18)$. The parlous state of services offered for injecting drug users in Russia was illustrated by a fire at a drug 
treatment hospital in Moscow in December 2006 which killed 45 mostly HIV-positive women. Hospital staff fled when the fire broke out, leaving patients trapped inside to die (20).

Overall harsh drug policies in many countries of the former Soviet Union have had particularly negative consequences for access to HIV testing, counselling and harm reduction interventions (13). In Russia, in 1998 possession of very small amounts of heroin (up to $0.005 \mathrm{~g}$ ) became punishable by imprisonment. Between 1997 and 2000, the number of those imprisoned for minor drug offences consequently increased fivefold. These provisions were repealed in December 2003, in effect decriminalizing possession of small quantities of illegal drugs. However, the Criminal Code was again revised in February 2006, criminalizing the possession of 0.5-2.4 g of heroin as "large scale" and $2.5 \mathrm{~g}$ and above as "especially large scale" (14). Another problematic aspect of drug legislation is that mandatory sentences are determined by the weight of drugs, rather than purity (16). This restrictive legal environment discouraged drug users from carrying needles and syringes, participating in needle exchange projects or accessing pharmacies, and constituted an incentive to engage in unsafe injecting practices, such as needle-sharing $(5,14,15,21)$.

Furthermore, prisons constitute a high-risk environment, generally characterized by overcrowding, poor nutrition, miserable physical conditions, corrupt and poorly trained prison staff and inadequate medical care. Male-to-male sex, the sharing of needles and the high prevalence of sexually transmitted diseases contribute to the spread of HIV in the region's prisons. Harm reduction measures, such as condoms and sterile injecting equipment, are generally absent. The region's penal systems have been described as "incubators for HIV and other infectious diseases" (22, 33). In 2004, the Russian Federation, with its 875,000 prisoners (611 per 100,000 population), had the world's highest incarceration rate after the United States (2.02 million prisoners, or 702 per 100,000) (22); the high rates in both cases are related to the a mass incarceration of drug users (16). In Russia, about $4 \%$ of the total prison population in 2002 was diagnosed as HIV positive (22). At present, many nonviolent injecting drug users in the region continue to be incarcerated, exacerbating the health risks to them and others (22).

Policing in the region has been generally dominated by law enforcement and drug control rather than questions of public health $(15-17,21)$. According to 101 interviews with drug users and sex workers in Ukraine, cases were common of police harassing, arresting, and severely beating drug users merely for possessing syringes. Police were even reported to confiscate antiretroviral drugs believing that these were recreational drugs (23). Research in Vinnitsya oblast in Ukraine in 2001 found that police had sent undercover agents to see whether they could purchase drugs from the social workers involved in the needle exchange intervention (24). In a qualitative study involving 27 police officers in the Russian city Togliatti in 2002 it was found that the predominant approach to policing drug users was punitive, based on street-based visibility and close surveillance of injecting drug users (14). Drug users were perceived as potential criminals and violence by police officers towards them was described as "an unavoidable feature of street surveillance" (14). Furthermore, pharmacies and syringe exchange sites were perceived as ideal places for police surveillance (14).

The study of police officers in Togliatti showed that a key strategy of surveillance was the official registration as drug addicts
(14). Indeed, all countries of the former Soviet Union have laws that provide for the compulsory registration of drug users when arrested by the police, with far-reaching consequences, such as a denial of government employment or public housing $(4,23)$. Injecting drug users in Russia who access drug treatment facilities are registered and monitored by the local drug treatment service for a period of 5 years following treatment (18). According to 86 interviews conducted with injecting drug users in Volgograd and Barnaul in 2003, fear of registration as drug user was one of the three main barriers to accessing treatment. Registration was associated with a loss of employment, breaches in confidentiality and stigma (18).

\section{Prejudice, Discrimination, and Ideology}

Members of the population groups at highest risk of HIV infection are often exposed to prejudice and discrimination, impeding their access to HIV prevention and care (7). In Russia, in 1997, a group of medical students even issued a statement proclaiming that "AIDS will destroy all drug addicts, homosexuals, and prostitutes. [... . Long live AIDS!” (2). Several studies have confirmed that negative public attitudes are widespread in many countries of the former Soviet Union. In Moldova, for example, the 2005 Demographic and Health Survey (DHS) found that only 11\% of respondents would buy fresh vegetables from a person with AIDS, and only $28 \%$ believed a female teacher with HIV should be allowed to keep her job (25). In 2005, another survey in Moldova found that $74 \%$ of respondents believed that HIV-positive people need to be isolated from society (26).

Drug users are often perceived as socially untrustworthy or unproductive (11) or generally "useless to society" (12) and this may be a reason why public opinion seems to be resolutely opposed to harm reduction interventions (12). In a qualitative study in Ukraine, injecting drug users were perceived as criminals and/or as individuals who lacked moral values and some medical service providers perceived them as hopeless cases who were impossible to treat (24). The opposition of Russian narcologists to substitution treatment has been described to be based on the conviction that illicit drug users are a "criminal class that needs to be put under control, and if necessary, isolation” (16). In focus group discussions in the Russian city of Samara in 2004, HIV was perceived as punishment for immoral behaviour, in particular sex work and drug use, and discriminating attitudes were also reported from medical professionals (27). In view of these attitudes it is perhaps not surprising that many people at risk do not get tested because of the stigma associated with injecting drug use and HIV and the fear of testing positive (24).

Sex work is also highly stigmatized and criminalized (28). Many sex workers are victims of violence and police harassment, making them more vulnerable to HIV/AIDS than would otherwise be the case $(22,29)$. Men who have sex with men also face high levels of prejudice. Homosexuality was a criminal offence in the Soviet Union and remains highly stigmatized across the region (19, 22, 30).

In line with the stigmatization of people living with HIV, as well as the widespread negative attitudes towards people who use drugs, discriminatory practices have been reported that extend to the provision of health services $(23,31)$. In many cases HIV-positive people are being segregated in stigmatizing AIDS centres (3). Physicians at AIDS centres, on the other hand, have declined to 
treat active drug users and instead referred them to narcological dispensaries that have the sole authority for treating addiction (11). Dental care, routine operations and emergency care have reportedly been denied to HIV-positive people $(3,11)$.

The reluctance of providing fully fledged interventions to those at highest risk of contracting HIV can be in part related to legacies of the communist past. In the Soviet Union, the issues of sex and drugs were taboo and there was no place for those who fell outside the idealized version of the new Soviet human being, such as injecting drug users, sex workers or men who have sex with men (12, 32).

According to interviews with 58 representatives of government and non-government organizations in the Volgograd region of the Russian Federation conducted in 2004, about a quarter of respondents mentioned cultural barriers to scaling-up harm reduction measures. Among those was the perception that harm reduction was a concept that originated in the West and was “imposed on Russia from outside" (12). Other observers noted that methadone is equally perceived as a plot against Russia (16). This draws attention to the ideological associations made with HIV programmes. A key issue in whether global health initiatives receive priority from national political leaders is how they are framed (33). In the case of HIV in the former Soviet Union, one reason for the resistance towards harm reduction measures and substitution treatment is apparently that these interventions are considered to be alien and even dangerous to the national context. This begs comparisons with the resistance in many quarters in Russia towards the introduction of the Directly Observed Treatment, Short-course (DOTS) strategy for managing tuberculosis, which was also seen as being imposed from outside and not applicable to Russia (34).

The religious sector also seems to stand in the way of necessary HIV interventions, as the Orthodox Churches are sometimes opposed to the implementation of HIV prevention and care programmes. This opposition is associated with the belief that health education fosters homosexuality - still a very delicate issue, as illustrated by the recent difficulties faced by organizers and participants of Gay Pride Parades in Russia or Moldova.

The status of science in the former Soviet Union is another obstacle to improving HIV prevention and treatment services in the region, as it is often characterized by isolation and ideology (35, 36). To a significant degree, Soviet science was based on ideology rather than evidence, with little awareness of research published in international journals and no desire to pursue rigorous evaluations of treatment procedures (37). These legacies continue to be felt today. In Russia, science is still following a strict hierarchical model, in which one institution (usually in Moscow) is nominated as "leading institution" and its director as the "leading specialist" in each field, a structure that is not conducive to innovation or critical dispute (35). As in Soviet times, there is still the myth that Russian science is world-leading (35). In reality, however, there is often an isolation from the international research community, with an estimated 95\% of doctors in Russia unable to read in English and the remaining 5\% often without the opportunity to access up-to-date research (35). Narcology officials in the Russian Federation have been strongly opposed to substitution treatment for opiate dependence (16). Partly due to a limited exposure to international research, they are advocating policies and practices which are totally unsupported by scientific evidence $(13,16)$. In what was one of the more extreme cases, Russian neurosurgeons aimed to destroy regions of the brain of more than 500 injecting drug users with the aim of controlling craving, a procedure that has now been discontinued (11).

\section{DISCUSSION}

While this paper has discussed some of the societal and attitudinal challenges that will need to be addressed when expanding HIV programmes in the former Soviet Union, it is important to remember that the factors that contributed to the spread of HIV in the region include the large-scale social and economic changes associated with transition (38), as well as the rapid diffusion of injecting drug use (19). Furthermore, it is worth noting that there are substantial differences across and within the different countries of this part of Europe. A study of the HIV context in Pskov and Samara regions and the Republic of Tatarstan, all Russian Federation, for example, found considerable differences in terms of, among others, the political environment, social attitudes to HIV, and civil society involvement. In Pskov region, HIV was framed mainly as an issue of drug control and antisocial behaviour, while in Tatarstan, HIV was perceived as a societal problem. Tatarstan offered comprehensive HIV prevention interventions in the penitentiary sector, while these were lacking in Pskov and Samara (39). Tatarstan is also home to one of the most successful HIV prevention programmes in the Russian Federation (15). Overall in Russia, however, federal authorities continue to be deeply suspicious of harm reduction initiatives $(15,40)$. It is therefore also the support of the federal agencies that Western agencies will need to secure to achieve sustainable impact (41). Furthermore, more needs to be documented on challenges to HIV programmes in other countries of the former Soviet Union.

UNAIDS recommends that countries should include antistigma strategies as integral components of their national AIDS plans, and invest in a broad range of activities, including public awareness campaigns and capacity-building for organizations and networks of people living with HIV and groups most at risk of HIV infection (5). Moldova's proposal to Round 8 of the Global Fund, with a planned start date of October 2009, is specifically focused on people living with HIV/AIDS (PLHA). The development of the proposal was mainly facilitated by the National League of PLHA and its NGOs. Around $90 \%$ of the total funds for the proposal will be disbursed through NGOs with a specific focus on social assistance, social protection, palliative care, and human rights protection and promotion for people living with HIV/AIDS. The proposal aims to improve the quality of life of PLHA and to strengthen the National League of PLHA (42).

In countries with injection-driven HIV epidemics, drug policy assumes a key role. In many countries laws, regulations, or policies are in existence that present obstacles to effective HIV services for injecting drug users (5). Often, illicit drug users are among the most vulnerable and marginalized, as they are often perceived as "social deviants, misfits and lawbreakers" (40). A number of countries have repressive policies regarding illicit drug use. In China, Malaysia, and Vietnam, among other countries, drug detoxification and rehabilitation are compulsory for injecting drug users and those convicted of drug trafficking are regularly executed by the state $(11,40)$. Even in a country like 
Switzerland, drug policy was for a long time characterized by strict prohibition, with police action aiming to repress drug dealing and consumption. However, this changed with the emergence of HIV/AIDS in the mid-1980s, and due to the advocacy efforts of a coalition of harm reduction advocates, harm reduction emerged as another pillar of drug policy, alongside general prevention, therapy, and police repression against large-scale trafficking (43). There is no reason to believe that countries like Russia could not follow this path.

This paper has explored some of the barriers to scaling up HIV programmes in the former Soviet Union that will need to be addressed to increase the effectiveness of policies that aim to reverse the epidemic. This will not always be easy. However, experience from other countries shows that public attitudes towards injecting drug users and people living with HIV can be changed, in no small part through the activities of AIDS activists. This will involve recognizing their humanity, ensuring that their human rights are respected and defended, and increasing their involvement and visibility in HIV prevention and treatment programmes. There is also a clear need for legislative changes that allow for substitution treatment and decriminalize drug use. Furthermore, the local evidence base on what works and what does not will need to be expanded, as well as access to evidence from elsewhere. While many of the findings reported here relate to the Russian Federation, there is reason to believe that similar challenges exist in many other countries of the former Soviet Union. More needs to be done to document challenges to HIV prevention and treatment programmes across the region, so that policy interventions can be more effective.

\section{Acknowledgements}

The author's work on health systems in Central and Eastern Europe is supported by the European Observatory on Health Systems and Policies. An earlier draft of this paper has been presented at the World Conference of Humanitarian Studies, Groningen, 4-8 February 2009 and the author is grateful for the comments received.

\section{REFERENCES}

1. Joint United Nations Programme on HIV/AIDS UNAIDS. 2009 AIDS epidemic update. Geneva: UNAIDS; 2009.

2. Field MG. HIV and AIDS in the Former Soviet Bloc. N Engl J Med. 2004 Jul 8;351(2):117-20.

3. Brown H. Russia's blossoming civil society holds the key to HIV. Lancet. 2006 Aug 5;368(9534):437-40.

4. Open Society Institute. Harm reduction developments: countries with injection-driven HIV epidemics [Internet]. New York: Open Society Institute; 2008 [cited 2008 Apr 10]. Available from: http://www.soros. org/initiatives/health/focus/ihrd/articles_publications/publications/developments_20080304/developments_20080304.pdf.

5. Joint United Nations Programme on HIV/AIDS UNAIDS. 2008 Report on the global AIDS epidemic. Geneva: UNAIDS; 2008.

6. Wallander CA. Russian politics and HIV/AIDS: the institutional and leadership sources of an inadequate policy. In: Twigg JL, editor. HIV/ AIDS in Russia and Eurasia. New York: Palgrave Macmillan; 2006. p. 33-55.

7. Bernitz BL, Rechel B. HIV data in Central and Eastern Europe: fact or fiction? In: Martic S, Lazarus JV, Donoghoe MC, editors. HIV/AIDS in Europe moving from death sentence to chronic disease management. Copenhagen: WHO Regional Office for Europe; 2006. p. 232-42.

8. Mason J. Linking qualitative and quantitative data analysis. In: Bryman A, Burgess RG, editors. Analyzing qualitative data. London: Routledge; 1994. p. 89-110.
9. Mays N, Pope C, Popay J. Systematically reviewing qualitative and quantitative evidence to inform management and policy-making in the health field. J Health Serv Res Policy. 2005 Jul;10 Suppl 1:6-20.

10. Bobrova N, Sarang A, Stuikyte R, Lezhentsev K. Obstacles in provision of anti-retroviral treatment to drug users in Central and Eastern Europe and Central Asia: a regional overview. Int J Drug Policy. 2007 Aug;18(4):31318.

11. Wolfe D. Paradoxes in antiretroviral treatment for injecting drug users: access, adherence and structural barriers in Asia and the former Soviet Union. Int J Drug Policy. 2007 Aug;18(4):246-54.

12. Tkatchenko-Schmidt E, Renton A, Gevorgyan R, Davydenko L, Atun R. Prevention of HIV/AIDS among injecting drug users in Russia: opportunities and barriers to scaling-up of harm reduction programmes. Health Policy. 2008 Feb;85(2):162-71.

13. Sarang A, Stuikyte R, Bykov R. Implementation of harm reduction in Central and Eastern Europe and Central Asia. Int J Drug Policy. 2007 Mar;18(2):129-35.

14. Rhodes T, Platt L, Sarang A, Vlasov A, Mikhailova L, Monaghan G. Street policing, injecting drug use and harm reduction in a Russian city: a qualitative study of police perspectives. J Urban Health. 2006 Sep;83(5):911-25.

15. Heimer R, Booth RE, Irwin K, Merson M. HIV and drug use in Eurasia. In: Twigg JL, editor. HIV/AIDS in Russia and Eurasia. New York: Palgrave Macmillan; 2006. p. 141-63.

16. Elovich R, Drucker E. On drug treatment and social control: Russian narcology's great leap backwards. Harm Reduct J. 2008 Jun 24;5:23.

17. Latypov A. Understanding post 9/11 drug control policy and politics in Central Asia. Int J Drug Policy. 2009 Sep;20(5):387-91.

18. Bobrova N, Rhodes T, Power R, Alcorn R, Neifeld E, Krasiukov N, et al. Barriers to accessing drug treatment in Russia: a qualitative study among injecting drug users in two cities. Drug Alcohol Depend. 2006 Apr;82 Suppl 1:S57-63.

19. Stachowiak J, Peryshkina A. NGOs and HIV in Russia: lessons from a unique case study. In: Twigg JL, editor. HIV/AIDS in Russia and Eurasia. New York: Palgrave Macmillan; 2006. p. 57-76.

20. Myers SL. 45 women die in fire at drug treatment hospital in Moscow. International Herald Tribune. 2006.

21. Csete J. Rights and lessons scorned: human rights and HIV/AIDS in Russia and Eurasia. In: Twigg JL, editor. HIV/AIDS in Russia and Eurasia. New York: Palgrave Macmillan; 2006. p. 165-79.

22. HIV/AIDS in Eastern Europe and the Commonwealth of Independent States. Reversing the epidemic: facts and policy options. Bratislava: United Nations Development Programme; 2004.

23. Human Rights Watch. Rhetoric and risk: human rights abuses impeding Ukraine's fight against HIV/AIDS. New York: Human Rights Watch; 2006.

24. Barcal K, Schumacher JE, Dumchev K, Moroz LV. A situational picture of HIV/AIDS and injecting drug use in Vinnitsya, Ukraine. Harm Reduct J. 2005 Sep 15;2(1):16.

25. National Scientific and Applied Center for Preventative Medicine. Moldova: demographic and health survey 2005 [Internet]. Calverton: National Scientific and Applied Center for Preventive; 2006 [cited 2008 Dec 26]. Available from: http://pdf.usaid.gov/pdf_docs/PNADH788.pdf.

26. International Labour Organization. Factsheet on HIV/AIDS discrimination at the workplace in Moldova [Internet]. Chisinau: International Labour Office; 2006 [cited 2008 Dec 26]. Available from: http://www.aids. md/files/library/2006/1174/ilo-factsheet-hiv-discrimination-moldova2006.pdf.

27. Balabanova Y, Coker R, Atun RA, Drobniewski F. Stigma and HIV infection in Russia. AIDS Care. 2006 Oct;18(7):846-52.

28. Betteridge G. CEE/CA: Report calls for decriminalization of sex work. HIV AIDS Policy Law Rev. 2006 Apr;11(1):29-30.

29. Crago AL, Rakhmetova A, Karadafov M, Islamova S, Maslova I. Central \& Eastern Europe and Central Asia: police raids and violence put sex workers at risk of HIV. HIV AIDS Policy Law Rev. 2008 Dec;13(2-3):71-2.

30. Kelly JA, Amirkhanian YA. The newest epidemic: a review of HIV/AIDS in Central and Eastern Europe. Int J STD AIDS. 2003 Jun;14(6):36171.

31. Republic of Moldova. Report on annual HIV/AIDS expenditures in the Republic of Moldova [Internet]. Chisinau: Ministry of Health of the Republic of Moldova; 2007 [cited 2008 Dec 26]. Available from: http://www. aids.md/files/library/2007/1642/nasa-moldova-report-2007-en.pdf.

32. Feshbach M. The early days of the HIV/AIDS epidemic in the former Soviet Union. Washington, DC: Woodrow Wilson International Center for Scholars; 2005. 
33. Shiffman J, Smith S. Generation of political priority for global health initiatives: a framework and case study of maternal mortality. Lancet. 2007 Oct 13;370(9595):1370-79.

34. Hønneland G, Rowe L. Health as international politics: combating communicable diseases in the Baltic sea region. Aldershot: Ashgate; 2004

35. Vlassov VV, Danishevskiy KD. Biomedical journals and databases in Russia and Russian language in the former Soviet Union and beyond. Emerg Themes Epidemiol. 2008 Sep 30;5:15.

36. Donoghoe MC, Lazarus JV, Matic S. HIV/AIDS in the transitional countries of Eastern Europe and Central Asia. Clin Med. 2005 SepOct;5(5):487-90.

37. McKee M. Cochrane on Communism: the influence of ideology on the search for evidence. Int J Epidemiol. 2007 Apr;36(2):269-73.

38. Moran D, Jordaan JA. HIV/AIDS in Russia: determinants of regional prevalence. Int J Health Geogr. 2007 Jun 6;6:22.

39. Atun RA, McKee M, Drobniewski F, Coker R. Analysis of how the health systems context shapes responses to the control of human immunodeficiency virus: case-studies from the Russian Federation. Bull World Health Organ. 2005 Oct;83(10):730-38.
40. Malinowska-Sempruch K, Bonnell R, Hoover J. Civil society - a leader in HIV prevention and tobacco control. Drug and Alcohol Rev. 2006 Nov;25(6):625-32.

41. Rowe L, Rechel B. Fighting tuberculosis and HIV/AIDS in Northeast Europe: sustainable collaboration or political rhetoric? Eur J Public Health. 2006 Dec;16(6):609-14.

42. Republic of Moldova. The Global Fund Proposal Summary - Round 8 , 2008 [Internet]. Chisinau: Centre for Public Health and Sanitary Management; 2008 [cited 2008 Dec 26]. Available from: [http://www.aids. $\mathrm{md} /$ coordination/consultation/global-fund-viii/.

43. Kübler D. Ideas as catalytic elements for policy change: advocacy coalitions and drug policy in Switzerland. In: Braun D, Busch A, editors. Public policy and political ideas. Cheltenham: Edward Elgar; 1999. p. 116-34.

Received August 31, 2009 Accepted in revised form February 18, 2010 